\title{
TOBACCOVID: A Vile in the Society!
}

\section{Arpit Sikri' ${ }^{*}$, Jyotsana Sikri², Amala Nancy $S^{3}$ and Ruben Lobo ${ }^{4}$}

${ }^{1}$ Associate Professor, Department of Prosthodontics, Bhojia Dental College and

Hospital, Budh (Baddi), Himachal Pradesh, India

${ }^{2}$ Senior Lecturer, Department of Conservative Dentistry and Endodontics, Bhojia

Dental College and Hospital, Budh (Baddi), Himachal Pradesh, India

${ }^{3}$ Dental Officer (Consultant Prosthodontist), Seventh-Day Adventist Hospital,

Thanjavur, India

${ }^{4}$ Head of Communications, Marketing and Events, Dentistchannel Online Pvt Ltd,

India

*Corresponding Author: Arpit Sikri, Associate Professor, Department of Prosthodontics, Bhojia Dental College and Hospital, Budh (Baddi), Himachal

Pradesh, India.

The use of tobacco, a common "stress-buster" among the youth, results in various bacterial as well as viral infections of the respiratory tract. This may lead to devastating effects on the lungs. Moreover, there has been increase in the ferocity of dreadful diseases like pneumonia and tuberculosis. This was the scenario in the preCOVID times.

Coronavirus disease also known as COVID-19 commonly caused by SARS-CoV-2 virus came into picture with a lot of devastation globally. In December 2019, the very 1st case was reported in the Huanan sea food market of Hubei province in Wuhan, China. Later, this tiny virus created a lot of havoc globally. The World Health Organization (WHO) later declared this virus as a "pandemic". A more rampant development i.e. combination of Tobacco with COVID (can be called as TOBACCOVID) is hounding the planet.

During this pandemic times, a very few and common questions arise in the minds of everyone. What is the frequency and intensity of COVID in tobacco smokers? Are they more prone to the disease? What all measures can be taken for tobacco control during these tough times? The answer to all these questions lie in the evidence based review studies.

Although, the literature supports the association of tobacco and coronavirus disease, but limited evidence is present. There is a de-
Received: May 22, 2021

Published: June 01, 2021

(C) All rights are reserved by Arpit Sikri., et al. finitive correlation of tobacco smoking and severity of the disease. The more the frequency, the more the disease. As previously discussed, smoking leads to impairment of the immune system functioning. Tobacco smoking have adverse effects on the respiratory tract thereby making the individual more prone to various types of respiratory infections. Over a longer period of time or prolonged tobacco smoking may prove to be fatal. Well, there have been a couple of reasons or etiological factors leading to COVID 19, out of which smoking tobacco has been found to be an important factor. One of the serious forms of COVID can be seen in comorbidities i.e. chronic obstructive pulmonary disorder (COPD) in combination with tobacco smoking. Not only this, another dangerous form is the Smokeless tobacco (SLT). Although this form had been associated in causing various respiratory symptoms and off lately has shown a strong association in spreading COVID-19. The smokeless form of tobacco is commonly kept in mouth, which is further mixed with the saliva and can result in splatters or aerosols in the environment further infecting others with the infection.

Ultrastructurally, the SARS-CoV-2 virus is known to bind the single receptor for this virus in the host cell (ACE-2, angiotensin-II) with the help of glycoproteins S-type transmembrane or spike proteins. ACE-2 is predominantly seen in alveolar epithelial cells and can further turn a molecule of adhesion for these viruses. In addi-

Citation: Arpit Sikri., et al. “TOBACCOVID: A Vile in the Society!". Acta Scientific Dental Sciences 5.7 (2021): 01-02. 
tion to this another enzyme known as furin can lead to entry of the virus inside. Cai., et al. evaluated that there is a definitive upregulation or enhanced expression of the genes encoding ACE- 2 protein. This definitely suggests simultaneous increase in the number of virus receptors. The virus can also lead to a differential or altered expression of ACE- 2 furthermore causing extreme reduction of the enzyme causing more severe disease and associated symptoms. It is due to this reason that the tobacco smokers have a greater predisposition to develop the illness.

In addition, repeated inhalation of smoke and frequent movement of the hands can lead to a greater chance of contamination and ultimately chances of developing COVID-19. In this way, tobacco smoke can behave like a carrier of viral particles, increasing the risk of this disease. Smoking carried out during the lockdown times has really worsened the situation including a number of factors like confinement of smoke at home, propensity of smoking in the family of smokers and the exposure of passive or the non-smokers in family of friend circle.

Keeping in view the devastating effects of tobacco and COVID, adequate measures need to be taken which may include mass awareness campaigns and motivation to reduce rather to quit the habit of smoking. However, more and more motivation is required in chronic smokers or even in the family of smokers to quit smoking as this may lead to bright chances of getting infection with coronavirus. Apart from this, the online counselling as a part of telemedicine and teledentistry to individuals and group of tobacco smokers has proved to be a boon in such individuals. Meanwhile, government and non-governmental organizations (NGOs) can play a pivotal role in reducing the number of tobaccovids.

In conclusion, it becomes the duty of all of us to convince and motivate the patients for tobacco cessation. A plethora of approaches can help us to reduce the number of tobaccovids. These may include a) Cautioning through mass awareness campaigns about the ill effects of tobacco, increase chances of getting COVID and poor prognosis b) Using innovative digital modalities like telemedicine consultations, video consultations, apps pertaining to tobacco control c) The use of electric cigarettes, electronic nicotine delivery system (ENDS) and hookahs to be discouraged d) Accentuating the smoke-free environment and its effects in resisting the COVID infections. So let us all take a pledge on the World No Tobacco Day to motivate the tobacco users to quit the habit of smoking. This totally abides by the theme of the World Health Organization (WHO) i.e. "Commit to quit".

\section{Volume 5 Issue 7 July 2021}

(C) All rights are reserved by Arpit Sikri et al. 